The Fossil Evidence for Human Evolution

An Introduction to the Study of Palaeosnthropology. By Sir Wilfrid E. Le Gros Clark. Second edition, revised and enlarged. (The Scientist's Library.) Pp. xii +201 . (Chicago and London: University of Chicago Press, 1964.) 6 dollars; 458.

$\mathrm{T}$ HIS revised edition of The Fossil Evidence for Human

Evolution comes at an appropriate time and 10 years after the original publication. In 1954, Piltdown had been relegated to the history of fakes and forgeriesand the human evolutionary picture was all the better for the removal.

The 10 years that have passed have seen fewer crises and the emergence of a much more satisfactory realization of man's ancestry. Much of this has depended on the labours of a few men: the prescience and persistence of Kenneth Oakley, who has added a new system of time to human studies; the labours of John T. Robinson on the splendid collections of Australopithecines that he has had to leave in South Africa on his translation to Wisconsin; and always the genius of L. S. B. Leakey in charming fossils from the ground.

All this has clarified the general view, if some aspects of it are a little clouded. Most systematists will heartily agree with Sir Wilfrid that there are too many names along the route of man's emergence. While it is true that in these pages Pithecanthropus and Sinanthropus are now less frequently mentioned and Homo erectus stands more neatly in their place, yet the Australopithecines bristle with genera from $A$ to $Z$. There is much to be said for the author's plea that, until they become systematically established, specimens might bear such names as "the Steinheim skull", the "Swanscombe skull", etc., rather than a too hasty attribution to a new genus and species. On the other hand, human palaeontology is of general interest and a new genus may more easily and more widely be recorded.

The increase in the size of the new text is largely due to valuable descriptions of the methods of dating remains. Fluorine, carbon-14, potassium-argon and uranium-lead are dealt with. It is interesting to note that dates in the Pleistocene are being lengthened and put further back. Homo sapiens had a history of 50 thousand years in the 1954 edition. Now it is 200 thousand.

This well-produced volume is a necessity for all who work in human palaeontology. Others will also appreciate the quiet wisdom and the well-turned phrases of its distinguished author.

W. E. SwINToN

\section{Mathematical Analysis}

Functions, Limits, Series and Continued Fractions (International Series of Monographs in Pure and Applied Mathematics, Vol. 69). Edited by L. A. Lyusternik and A. R. Yanpol'skii. Translated by D. E. Brown. Pp. xiv +404. (Oxford, London and New York: Pergamon Press, 1965.) $70 s$.

7 HE content of Mathematical Analysis is somewhat wider than the sub-title suggests. There is a chapter on $n$-dimensional spaces, functions defined there, linear operators, convex bodies; the work on series includes a considerable amount of material on orthogonal series and systems of orthogonal polynomials; there is a short section on special functions, such as the Bernoulli and Euler numbers, the elliptic functions, the gamma function, Bessel functions. The material is logically arranged and clearly set out, but no theorems are proved. It is thus difficult to know how the book is to be used, and it is a pity that the editors do not tell us how this and succeeding volumes fit into the Russian techniques of instruction. The arrangement is scarcely suitable for a book of reference, but the absence of proofs would prevent it being an adequate text for private study. If a tescher were to select the more difficult key theorems and go through them in detail with his pupils, they might then, granted time and patience, derive very substantial benefit by working carefully through the rest of the book, proving the subsidiary theorems and verifying the numerous formulae. There is, for example, an immense amount of information stored away in the chapter on orthogonal polynomials; and to verify the couple of dozen integral forms, not all entirely trivial, for Catalan's constant would make an admirable revision exercise in the technique of definite integrals. Perhaps if later volumes are translated, a prefatory word on how best to use them could be added. T. A. A. Broadbent

\section{Power Travelling-wave Tubes}

(Applied Physics Guides.) By J. F. Gittins. Pp. xii +276. (London : The English Universities Press, Ltd., 1964.) $50 s$.

TRAVELLING-WAVE tubes have played such a unique part in the development of microwave communication links that they well merit close examination. Not only in their conception are they the result of an impressive flight of imagination, but also in their construction they incorporate some of the most recent technologica] developments.

Power Travelling-wave Tubes gives a very successful presentation of most problems involved in the design of travelling-wave tubes. In view of the emphasis put these days on the importance of advanced engineering education, it is encouraging to find a book which is prepared to tackle not only the fundamental but also the technological side of a problem.

The author discusses both forward and backward wave amplification processes, including erossed-field interaction. The operating of travelling-wave tubes is explained using Pierce's approach, but a commendable use is made of vector diagrams to illustrate many points. Separate chapters discuss slow-wave structures, electron guns and collectors and transitions, severs and radiofrequency windows. The two final chapters deal specifically with vacuum and measurement techniques.

The book can be recommended as an up-to-date description of an important field of vacuum tube technology and it is a welcome addition to technical literature.

\section{P. A. LINDSAY}

\section{Structure Antigénique de Tumeurs Expérimentales}

Par C. Deckers. Pp. 180. (Bruxelles: Editions Arscia S.A.; Paris: Librarie Maloine, S.A., 1964.) n.p.

CHIS is a monograph covering several years' work by Dr. Deckers, dealing with the analysis of antigens in rat tumours by the methods of Ouchterlony double diffusion and immunoelectrophoresis. Several methods for increasing the sensitivity of the gel diffusion technique were deseribed. The most sensitive of these used a combination of immunoelectrophoresis and double diffusion in gel. Hyperimmune rabbit sera were used in all the investigations involving rat tissues. Five organ-specific liver antigens were demonstrated in normal rat liver. During the course of chemical carcinogenesis of the liver, the concentration of organ specific antigens progressively diminished. In transplantable hepatomata, there was only one such antigen remaining. However, a new antigen was detected in a transplantable (HA) hepatoms. This new antigen could not be detected in other tumours. Attempts to provoke circulating antibodies to the HA antigen in rats were unsuccessful, as far as the means of detection would allow. Inoculation of rats with HA tumour extracts either slightly decreased or increased the rate of growth of tumours transplanted later.

The efforts of some of the other workers in this field were mentioned. The author deserves credit for persisting in a problem which poses many experimental difficulties, and it will be interesting to follow the progress of the work. ROBERT R. DOURMASHKIN 